Article

\title{
A Case Study of Socially-Accepted Potentials for the Use of End User Flexibility by Home Energy Management Systems
}

\author{
Christian Pfeiffer*(D), Markus Puchegger (D), Claudia Maier (D), Ina V. Tomaschitz (D), Thomas P. Kremsner \\ and Lukas Gnam (D) \\ Forschung Burgenland GmbH, Campus 1, 7000 Eisenstadt, Austria; \\ markus.puchegger@forschung-burgenland.at (M.P.); claudia.maier@forschung-burgenland.at (C.M.); \\ ina.tomaschitz@forschung-burgenland.at (I.V.T.); thomas.kremsner@forschung-burgenland.at (T.P.K.); \\ lukas.gnam@forschung-burgenland.at (L.G.) \\ * Correspondence: christian.pfeiffer@forschung-burgenland.at; Tel.: +43-5-7705-5433
}

Citation: Pfeiffer, C.; Puchegger, M.; Maier, C.; Tomaschitz, I.V.; Kremsner, T.P.; Gnam, L. A Case Study of SociallyAccepted Potentials for the Use of End User Flexibility by Home Energy Management Systems. Sustainability 2021, 13, 132. https://dx.doi.org/10 $.3390 / \mathrm{su} 13010132$

Received: 20 November 2020 Accepted: 22 December 2020 Published: 25 December 2020

Publisher's Note: MDPI stays neutral with regard to jurisdictional claims in published maps and institutional affiliations.

Copyright: () 2020 by the authors. Licensee MDPI, Basel, Switzerland. This article is an open access article distributed under the terms and conditions of the Creative Commons Attribution (CC BY) license (https: / / creativecommons.org/ licenses/by/4.0/).

\begin{abstract}
Due to the increase of volatile renewable energy resources, additional flexibility will be necessary in the electricity system in the future to ensure a technically and economically efficient network operation. Although home energy management systems hold potential for a supply of flexibility to the grid, private end users often neglect or even ignore recommendations regarding beneficial behavior. In this work, the social acceptance and requirements of a participatively developed home energy management system with focus on (i) system support optimization, (ii) self-consumption and self-sufficiency optimization, and (iii) additional comfort functions are determined. Subsequently, the socially-accepted flexibility potential of the home energy management system is estimated. Using methods of online household survey, cluster analysis, and energy-economic optimization, the socially-accepted techno-economic potential of households in a three-community cluster sample area is computed. Results show about a third of the participants accept the developed system. This yields a shiftable load of nearly 1.8 MW within the small sample area. Furthermore, the system yields the considerably larger monetary surplus on the supplier-side due to its focus on system support optimization. New electricity market opportunities are necessary to adequately reward a systemically useful load behavior of households.
\end{abstract}

Keywords: user acceptance; social acceptance; home energy management system; end user flexibility; flexibility potential

\section{Introduction}

The energy system is subject to a sustained transformation due to the increase of volatile renewable energy resources. Additional variations of infeed and purchase, i.e., flexibility [1], will be necessary in the electricity system in the future in order to continue a technically and economically efficient and secure network operation [2].

Private end users can provide flexibility, for example, by expanding heat pumps, charging stations, and storage systems through adapting to current power requirements, thus adapting their energy demand by shifting their loads to different times (e.g., use of washing machine) or by feeding power back into the grid [3]. Investments in photovoltaic (PV) systems and energy storage solutions are advantageous for both energy suppliers and private end users, as they all profit from increased flexibility in the energy system [4]. Furthermore, home energy management systems (HEMSs) give users the opportunity to gain insight into their energy consumption behavior and receive recommendations to change their behavior in a sustainable way, yielding savings for both energy and costs [5].

Although HEMSs are already well accepted in general, users' skepticism, e.g., due to anxiety concerning new technologies, occasionally occurs [6]. This is particularly the case if their objectives and HEMSs' feedback concerning their energy consumption behavior are in conflict (e.g., if a comfortable lifestyle needs to be changed [7]). To prevent users 
from ignoring the feedback provided by HEMSs, it is of utmost importance to increase the awareness of the benefits and advantages provided by such systems and, subsequently, increase user acceptance [8]. Examples of attractive benefits include cost savings, environment protection, comfort, energy independence, and possibility to control appliances in an innovative way, as well as social aspects, like being a role model, being part of a community, competition, and fun [9]. However, users often value monetary benefits higher than contributing to a community [10]. Another important factor is innovativeness and the utility of HEMSs [11], the latter being even more important than the ease of use when affecting the consumers' intention to use [12]. Besides device control and energy monitoring, one key feature of HEMSs is the prediction of energy consumption patterns, as well as energy generation opportunities [13]. Weather forecasts enable estimation of future energy generation, for example, through PV or solar systems. Due to this indication, home energy usage can be scheduled automatically by the system. Alternatively, the provided information by HEMSs empowers the users (i) to contribute to grid optimization [14] and (ii) to optimize their self-consumption and self-sufficiency [15]. As further added value, HEMSs provide (iii) additional comfort functions [16].

\subsection{Motivation}

This paper is focused on HEMSs that address these aspects, their social acceptance, and techno-economical potentials. Therefore, the following sections give a more detailed description of these different HEMS aspects.

\subsubsection{Grid Optimization}

Operating a power system with a high level of renewable energy requires devices for grid balancing. Due to the high volatility and low predictability of renewable energy sources, the balancing of energy production and consumption remains challenging [17].

Prosumers can use the distributed energy generation (mainly PV) to increase the direct consumption of the objects, thereby saving network charges and taxes. In energy markets where there is no substantial support for renewables, there is an economic incentive for self-consumption of PV or increase of the self-sufficiency as the selling prices for PV power are typically lower than retail prices for power [18]. For the energy supplier, the immediate consumption of self-generated electricity by prosumers leads to lower sales and, thus, to a lower contribution margin. The supplier could use the remaining flexibility after optimizing the customer's own consumption to benefit from low energy price periods in electricity wholesale [19].

With respect to grid support, forecasts of energy consumption and generation computed by HEMSs utilizing the available household data provide direct benefits. The retrieved data from energy suppliers give HEMSs the opportunity to reduce strain on the grid, therefore enabling control whether and where investments in the grid are necessary and, subsequently, optimizing the grid for consumers' usage [14]. Moreover, due to accurate predictions, energy demand peaks and times of high renewable energy production can be identified and managed efficiently [20]. This gives energy suppliers the opportunity to structure their supply flexibly according to demand [13]. Such an efficient management approach, in turn, avoids energy waste. However, if users are encouraged to reschedule appliances from peak hours to regular hours due to grid optimization activities, they may feel restricted and perceive comfort decreases [7]. This could possibly be counteracted if the utility offers discounts for load shifting [21].

\subsubsection{Self-Consumption and Self-Sufficiency Optimization}

In general, the performance of an individual household's PV can can be characterized by two interacting metrics: self-consumption and self-sufficiency. The former is defined as the percentage of self-consumption relative to the total electricity production, whereas the latter describes the percentage of self-consumption compared to the total electricity consumption [22]. To optimize the users' energy consumption, HEMSs recommend to shift 
their activities [23]. In combination with PV systems, these recommendations subsequently increase both the self-consumption and the self-sufficiency. Ideally, HEMSs enable users to avoid energy waste and monitor energy consumption, which is subject to the condition that end users comprehend its content [24]. HEMSs either analyze the entire building, individual rooms, or single appliances [23]. Presentation of energy consumption data at appliance level increases users' comprehension and processing of the shown information as the disaggregated illustration helps end users to relate the data to their personal activities [11]. Furthermore, HEMSs support end users to identify and track devices that consume large amounts of electricity, thus creating a cost saving potential by presenting consumption data at appliance level [25]. A user-friendly interface that emphasizes specific data relevant for the respective user is crucial [11]. Another feature regarding energy consumption optimization that users expect from HEMSs is to remotely switch on and off devices that are currently not in use [6]. Besides the self-consumption and self-sufficiency optimization component, this offers an additional comfort function, as outlined in Section 1.1.3.

An increase of the self-sufficiency can be achieved with microgrid management approaches. A model predictive control-based energy scheduling in a smart microgrid enables a maximized utilization of up to $90 \%$ of the production of a PV plant. Based on the available data provided by weather forecasts and user behavior profiles, HEMSs enable the prediction of energy generation and consumption of households and, therefore, a more balanced energy management [26]. In a broader sense, HEMSs that use scheduling approaches based on prediction parameters and consumption patterns foster the energy independence of local energy communities with prosumers and consumers that trade energy with each other [27].

Microgrids that include fluctuating renewable energy generation and end user-related demand side management or demand response are considered stochastic systems. Essential parts of scheduling approaches in such stochastic systems are robust optimization strategies to balance forecast inaccuracies in generation or unforeseen user behavior. For example, multi-criteria optimization models can be used to address the conflict of interest between system support optimization, self-consumption and self-sufficiency optimization, and user comfort [28].

\subsubsection{Additional Comfort Functions}

HEMSs provide several comfort factors that increase user acceptance, e.g., thermal comfort (temperature), humidity and airflow, air quality $\left(\mathrm{CO}_{2}\right.$ concentration), or visual comfort (illumination) [16], which is perceived differently depending on the age of the individual person. Due to a worsening of their eyesight, elderly tend to favor luminescent spaces [20]. In general, color changing lights can provide a pleasant atmosphere [29]. Additionally, automatic prediction of user parameters is a possibility to increase user comfort [25], especially for elderly or disabled persons, as it helps to interact with the system [30]. It enables relatives to remotely control appliances in their homes [10]. HEMSs, furthermore, increase the comfort factor by scheduling certain devices, like a washing machine, in accordance with the need of users [31]. In addition, the security factor is increased, e.g., by switching lights on and off automatically if residents are absent for a longer period [29] or by alarming emergency services in case of an emergency [25]. As smart homes often require the usage of appliances from the same vendor, users may feel restricted by HEMSs [20]. Therefore, compatibility is also a relevant comfort factor to consider when developing HEMSs.

\subsection{Problem and Research Need}

HEMSs offer several benefits to the environment, to the grid, and to users. However, the intention to follow the recommendations given by HEMSs and to adopt energy-saving behaviors not only depend on the technology itself but also on the characteristics of the individual person. The literature distinguishes between two ways to reduce energy consumption: (i) energy conservation (users change their behavior in order to save energy in everyday life) and (ii) energy efficiency (implementation of new, improved, and more effi- 
cient energy saving technologies) [32]. Many social and psychological factors (e.g., attitude, values [6]) determine whether people opt for one of the mentioned energy saving measures [33]. In addition, the economic aspect (costs vs. benefits), income level, and age group also need to be considered [34]. Therefore, flexibility provided by PV, energy storages, and HEMSs may only lead to theoretical potentials for a real supply of flexibility to the electricity grid as private end users often neglect or even ignore external recommendations of HEMSs regarding beneficial behavior [35].

To convince users to implement HEMSs and follow their recommendations, a participatory inclusion of end users and user-friendly HEMSs are essential to tap potential flexibility beneficial for the electricity system [36]. It is necessary to investigate the factors that are primarily responsible for driving user acceptance concerning the use of HEMSs and how they link to the users' needs concerning comfort, self-consumption, and self-sufficiency optimization with the grid's requirements and optimization. Furthermore, the factors negatively influencing the intention to use HEMSs must be considered to develop appropriate strategies for motivating users to engage with them [6]. To use such strategies in a targeted manner, potential user groups can be identified. Cut-off factors, like individual motivation (e.g., economic benefit), social motivation (e.g., environmental responsibility), and personal characteristics (e.g., openness for innovations), can be used [12].

This work addresses the points mentioned above. To date, most of the research results on HEMSs' grid support focus on their technological components. For example, in Reference [14], the impact of different control and forecasting algorithms on HEMSs was assessed. There is a gap of knowledge for grid-supportive and socially-accepted HEMSs. Research results on social acceptance are available in Reference [10]. The authors conducted a qualitative research on smart meter technologies but did not analyze the flexibility potentials given by the individual users. Based on a quantitative survey, in Reference [37], the energy consumption in residential buildings and, subsequently, flexibility potentials were investigated. However, the intention to use HEMSs and their flexibility potentials were not part of the research.

Several different studies focused on the analysis of general flexibility potentials in the power system. For example, the authors in Reference [38] simulated the grid flexibility based on a virtual energy storage on a regional level. In Reference [39], the flexibility of building energy systems in terms of time, power, and energy, aggregated on a city district level, was analyzed. Nuytten et al. determined the flexibility of a combined heat and power system coupled to a thermal energy storage solution [40]. The flexibility potentials of industrial loads are evaluated in Reference [41] according to a process of related loadcharacteristic data analysis. Due to the technical focus of the research mentioned above, an evaluation of the social acceptance of the proposed solutions to gather a socially-accepted flexibility potential was neglected.

The demand response flexibility of residential smart appliances was estimated in Reference [42]. By adhering to comfort requirements of the user, the authors addressed a social component in their estimation. However, no active user interaction with HEMSs was part of the research. Social factors are mostly considered assumptions into the devised models. The authors in Reference [43] developed flexibility algorithms used for HEMSs that address stakeholder needs using a theoretical social component in their model.

To the best of the authors' knowledge, determining a realizable flexibility potential based on actual user acceptance has not been researched extensively. Therefore, the acceptance of a participatively developed HEMS with focus on (i) system support optimization by consumption in times of high renewable production and utilizing grid flexibility, (ii) selfconsumption and self-sufficiency optimization, and (iii) additional functions for increased comfort and its requirements factors are presented. This information is used to explore the market potential and, subsequently, the effects on system support optimization and own-consumption of renewable production.

First, the techno-economic optimization potential of a three-community cluster sample in eastern Austria was evaluated in this case study. Second, the user acceptance and 
requirements of the HEMS was determined by means of an online survey in the sample area. Third, the survey results were combined with the techno-economic operation strategy of the developed HEMS to evaluate the final socially-accepted potential for the energy-economic deployment in the sample area.

\subsection{Outline}

The paper is structured as follows: Section 2 describes the framework of the case study, the functionality of the developed HEMS, the participants that took part in the survey, and the applied survey constructs, as well as the methods used for survey analyses and flexibility potential estimation. The results for the techno-economic and social potential are stated in Section 3. Section 4 shows a discussion, and Section 5 the conclusions of this case study.

\section{Materials and Methods}

To assess the socially-accepted potential for the use of end user flexibility by the participatively developed HEMS, it is necessary to initially analyze the technical and infrastructural framework for providing flexibility in the energy system of the sample area.

\subsection{Framework and HEMS Functionality}

In terms of energy economic potential, previous work [44] identified thermal flexibility linked with electrical driven space heating and hot water production as the most suitable type of flexibility in the sample area. Due to the the basic controllability of the flexibility, infrared heating does not play a role in the sample area. In addition, night storage heaters are not considered, since they are not easily controlled externally without further ado.

Based on these parameters, only hot water boilers and heat pumps are considered items with flexibility for the HEMS. Depending on the type of the application, they can be operated in pure ON/OFF mode or power-controlled (e.g., via a 0-10 V signal corresponding to $0-100 \%$ of the boiler's or heat pump's power). The building's internal control works exclusively via the developed HEMS, which sends a control signal to the hot water boiler/heat pump based on the measurement signals and external information. The HEMS is connected via WLAN or directly to the internet and thus communicates with the supplier's control room, which provides grid and energy system relevant recommendations [44].

\subsection{Survey Participants, Procedure, and Measures}

To assess the social acceptance for the developed HEMS, a questionnaire covering relevant acceptance and requirements factors was set up. This questionnaire was sent by e-mail to the current 521 users of the local cluster utility. In order to achieve a better response rate, the users could take part in a raffle for vouchers worth 50 EUR. During the first four days, 62 customers were reached who opened the questionnaire. After five days, a reminder e-mail was sent out. In the remaining ten days, another 34 answers were collected. In the course of data cleansing, one duplicate answer was removed, and two other answers were excluded due to insufficient data quality. This results in a response rate of $17.85 \%$. The final sample consists of $n=93$ potential users of HEMSs, which leads to a sample error of $4.61 \%$.

Of those surveyed, the majority are male (63\%) between the ages of 20 and 78 . Their mean (M) age is 50.93, with a standard deviation (SD) of 14.99. Thirty-one percent of the respondents have a school-leaving certificate or a tertiary education as the highest completed education. Fifteen percent have completed intermediate vocational schools, and less than a quarter $(23 \%)$ has completed an apprenticeship. Sixty-five percent live in single-family houses with floor spaces of $177.60 \mathrm{~m}^{2}$ on average $(\mathrm{SD}=52.26)$, and $11 \%$ live in two-family houses or of larger size $(M=261.30, S D=158.75)$. The remaining $23 \%$ of the participants live in flats $(\mathrm{M}=78.00, \mathrm{SD}=10.98)$. Most frequently, the respondents' households consist of two persons (41\%); households with four or more persons are also 
common (31\%). Twenty-eight percent of the households with more than one person have children. Twenty-three percent of the participants stated that they had already installed a PV system, typically with a rated output of 3 to $5 \mathrm{~kW}_{\mathrm{p}}$. Main participant sociodemographics are stated in Table 1.

Table 1. Participant sociodemographics.

\begin{tabular}{|c|c|c|c|}
\hline Sociodemographics & $\mathbf{M}$ & (SD) & $\%$ \\
\hline \multicolumn{4}{|l|}{ Gender } \\
\hline Female & & & 35.90 \\
\hline Male & & & 64.10 \\
\hline Age (years) & 50.93 & (14.99) & \\
\hline \multicolumn{4}{|l|}{ Education } \\
\hline Apprenticeship & & & 23.10 \\
\hline Intermediate vocational school & & & 15.30 \\
\hline School-leaving certificate & & & 30.80 \\
\hline University degree & & & 30.80 \\
\hline \multicolumn{4}{|l|}{ Housing and floor space $\left(\mathrm{m}^{2}\right)$} \\
\hline Flat & 78.00 & $(10.98)$ & 22.50 \\
\hline Single-family house & 177.60 & $(52.26)$ & 65.20 \\
\hline Two-family house or larger & 261.30 & (158.75) & 11.20 \\
\hline Other & 90.00 & - & 1.10 \\
\hline \multicolumn{4}{|l|}{ Household size } \\
\hline 1 person & & & 8.70 \\
\hline 2 persons & & & 40.90 \\
\hline 3 persons & & & 18.60 \\
\hline 4 or more persons & & & 30.80 \\
\hline \multicolumn{4}{|l|}{ Children living in household } \\
\hline None $\quad$ o & & & 72.00 \\
\hline 1 child & & & 15.80 \\
\hline 2 children & & & 11.00 \\
\hline 3 or more children & & & 1.20 \\
\hline
\end{tabular}

$n=93, \mathrm{M}=$ means, $\mathrm{SD}=$ standard deviations.

To ensure fully representative statements, and thus a valid basis to determine the technical and social potential for the energy-economic deployment, weighting was done according to the standard integrated EU-SILC design [45] stated in Equation (1):

$$
1 / C \leq \frac{\left(q_{i j} / \bar{q}\right)\left(w_{i j} / \bar{w}\right)}{\left(d_{i j} / \bar{d}\right)} \leq C .
$$

$C$ is a constant trimming value (which is set to the recommended value of $C=3$ according to Reference [45]) to recode extreme weights to more acceptable values, $q$ is the non-response correction with mean non-response $\bar{q}, w$ is the calibration in terms of age, gender, and level of education with mean $\bar{w}$, and $d$ corresponds to the design weights, each for observation $i=1, \ldots, n$ with household size $j=1, \ldots, 4$ as design characteristic with mean $\bar{d}$.

The sample size is considered sufficient due to (i) the relatively small sample error, (ii) the accurate representation of the population structure [46], (iii) the extensive weighting procedure, and (iv) the exploratory character of the case study at hand.

To measure the relevant acceptance and requirements factors, proven instruments, such as the Environmental Attitudes Inventory (EAI) [47], the Technology Usage Inventory (TUI) [48], or the Technology Acceptance Model (TAM) [49], are used with respect to the project context. Furthermore, scales from previous work are adopted [50]. 
Personal conservation behavior. Personal conservation behavior (COB) is measured with four items on a 1 = strongly disagree to 5 = strongly agree scale adopted from the EAI, e.g., "I always switch the light off when I don't need it on any more" $(\alpha=0.69)$.

Trust in science and technology. Trust in science and technology (TST) is measured on a 1 = strongly disagree to 5 = strongly agree scale adopted from the EAI. Three items were used to comprise the TST scale, e.g., "Modern science will be able to solve our environmental problems" $(\alpha=0.69)$.

Curiosity. Curiosity (CUR) is measured on a $1=$ strongly disagree to $5=$ strongly agree scale adapted from the TUI, e.g., "I am curious about the use of innovative energy and environmental solutions" ( $\alpha=0.89)$.

Interest. Interest (INR) is measured on a $1=$ strongly disagree to $5=$ strongly agree scale adopted from the TUI, e.g., "In the course of my life, I have acquired a lot of technical knowledge" $(\alpha=0.87)$.

Technology anxiety. Technology anxiety (ANX) is measured with four items on a 1 = strongly disagree to 5 = strongly agree scale adapted from the TUI, e.g., "The idea of doing something wrong when using technical equipment scares me" $(\alpha=0.72)$.

Skepticism. Skepticism (SKE) is measured on a $1=$ strongly disagree to $5=$ strongly agree scale adapted from the TUI, e.g., "The HEMS solution will disrupt my daily routine" $(\alpha=0.64)$.

Usefulness. Four items are used to measure the perceived usefulness (USF) on a 1 = strongly disagree to 5 = strongly agree scale adapted from the TAM, e.g., "Using the HEMS solution would make many things more convenient" $(\alpha=0.81)$.

Usability. The perceived ease of use, or simply usability (USB) is measured on a 1 = strongly disagree to 5 = strongly agree scale adapted from the TAM, e.g., "Using the HEMS solution is easy to understand" $(\alpha=0.76)$.

Accessibility. Accessibility (ACC) is measured on a $1=$ strongly disagree to $5=$ strongly agree scale adapted from the TUI. Three items are used to comprise the ACC scale, e.g., "I think that the HEMS solution can be afforded by almost anyone" $(\alpha=0.67)$.

Savings. The importance of cost savings (SAV) is measured using four items on a $1=$ not important at all to $5=$ very important scale taken from previous work, e.g., "To achieve rapid cost savings with the HEMS solution" $(\alpha=0.82)$.

Comfort increase. The importance of comfort increase (CMF) is measured using five items on a $1=$ not important at all to $5=$ very important scale taken from previous work, e.g., "Shutter control" $(\alpha=0.80)$.

Monitoring. The importance of monitoring $(\mathrm{MON})$ is measured on a $1=$ not important at all to $5=$ very important scale. Seven items are used to comprise the scale taken from previous work, e.g., "To be constantly informed about my current energy consumption" $(\alpha=0.84)$.

Sustainability. The importance of sustainability (SUS) is measured using six items on a $1=$ not important at all to 5 = very important scale taken from previous work, e.g., "To support the use of renewable energy sources" $(\alpha=0.88)$.

Intention to use. Intention to use (ITU) is measured on a $1=$ strongly disagree to 5 strongly agree scale adapted from the TAM. Three items are used to comprise the ITU scale, e.g., "I would purchase the HEMS solution" $(\alpha=0.92)$.

\subsection{Analysis of the Socially-Accepted Flexibility Potential}

The calculation of optimization potentials for heating devices in households was done by a MATLAB tool that uses various input and output data (e.g., electric load curves, thermal losses, wholesale prices). A detailed description of the MATLAB tool, including the input parameters, can be found in Reference [51]. Basic assumptions for the adoption of optimization in households are that (i) the customer will have no comfort losses and (ii) no financial disadvantages. As by assumption the point of time of the energy usage does not affect the costs for households, positive financial effects can only be provided for the households when producing electricity on site (via PV). Nevertheless, any savings 
generated for the energy supplier could also be shared with the end users. Therefore, also potentials on optimizing households without own production are investigated. Focus of optimization efforts is to maximize the on-site production (if there is any) in a first step and then using the remaining flexibility to load the hot water storages at times of low energy prices on the wholesale market in a second step.

The potential estimation is conducted in a bottom-up manner. Therefore, typical households with heat pumps and hot water boilers were created and simulated. In the sample area are 2821 households with a total number of 6529 inhabitants residing in 1951 buildings [46]. Of these households, 823 live in flats and 237 in single-family houses with electric water heaters. In 2017, about $7.5 \%$ of residential units in the corresponding federal state were heated with electric heat pumps. Applying this value to the number of buildings in the sample area results in approximately 146 buildings heated with heat pumps [52]. For the basic scenario, it is assumed that about $10 \%$ of the single family houses own a PV system with a nominal power of $5 \mathrm{~kW}_{\mathrm{p}}$. This assumption is based on the number of buildings in Austria, which is 2,191,280 [53], and the installed PV capacity on buildings in Austria, which is $1037 \mathrm{MW}_{\mathrm{p}}$ [54].

To explore the market potential of the developed HEMS, a k-means cluster analysis based on the acceptance and requirements dimensions is conducted. Finally, those clusters with the highest level of acceptance are used to estimate the socially-accepted flexibility potential.

\section{Results}

The relevant housing infrastructure in the sample area is shown in Table 2. Eight hundred and twenty-eight flats are considered. From the 237 single-family houses with electric water boilers, 24 are equipped with a PV system and 15 buildings with heat pumps, assuming the typical peak power of $5 \mathrm{~kW}_{\mathrm{p}}$. Two hundred and thirteen of the single-family houses have neither a heat pump nor a PV system.

Table 2. Number and structure of relevant households.

\begin{tabular}{|c|c|c|c|c|c|}
\hline \multirow{2}{*}{ Household Type } & \multirow{2}{*}{ Flat } & \multicolumn{4}{|c|}{ Single-Family House } \\
\hline & & Type 1 & Type 2 & Type 3 & Type 4 \\
\hline Heating demand ${ }^{\text {a }}$ & not relevant & not relevant & not relevant & 41 & 41 \\
\hline \multicolumn{6}{|l|}{ Space heating } \\
\hline Producer & - & - & - & heat pump & heat pump \\
\hline Thermal power ${ }^{\mathrm{b}}$ & - & - & - & 7.0 & 7.0 \\
\hline \multicolumn{6}{|l|}{ Hot water } \\
\hline Producer & hot water boiler & hot water boiler & hot water boiler & heat pump & heat pump \\
\hline Thermal power ${ }^{b}$ & 4.5 & 4.5 & 4.5 & 7.0 & 7.0 \\
\hline Electric power ${ }^{b}$ & 4.5 & 4.5 & 4.5 & 2.3 & 2.3 \\
\hline \multicolumn{6}{|l|}{$P V$ system } \\
\hline Peak power ${ }^{b}$ & - & - & 5.0 & - & 5.0 \\
\hline \multicolumn{6}{|l|}{ Heat storage } \\
\hline Water ${ }^{c}{ }^{\circ}$ & 110 & 110 & 110 & 300 & 300 \\
\hline Heating buffer ${ }^{c}$ & - & - & - & 600 & 600 \\
\hline Number of households & 823 & 213 & 24 & 131 & 15 \\
\hline
\end{tabular}

${ }^{\mathrm{a}} \mathrm{kWh} / \mathrm{m}^{2} \mathrm{a},{ }^{\mathrm{b}} \mathrm{kW},{ }^{\mathrm{c}}$ liter.

Table 3 shows the results for the techno-economic potential for households and energy suppliers in the given setting. The baseline scenario for households is the on-off control for the storage, where the heating device switches on when the storage reaches its minimum and switches off when it reaches its maximum. The baseline scenario for the energy supplier is different for households with own consumption, where it is assumed that the households optimize their own consumption individually. Households with a PV system 
have a surplus on the customer side. The highest average surplus is achieved in household type 4 with a heat pump and a PV system.

Table 3. Techno-economic potential of households.

\begin{tabular}{|c|c|c|c|c|c|c|}
\hline \multirow{2}{*}{ Household Type } & \multirow{2}{*}{ Flat } & \multicolumn{4}{|c|}{ Single-Family House } & \multirow{2}{*}{ Total } \\
\hline & & Type 1 & Type 2 & Type 3 & Type 4 & \\
\hline \multicolumn{7}{|l|}{$\begin{array}{l}\text { Surplus per } \\
\text { household }\end{array}$} \\
\hline Customer-side a & - & - & 10.37 & - & 22.41 & \\
\hline Supplier-side ${ }^{a}$ & 10.51 & 10.51 & 8.55 & 25.83 & 20.08 & \\
\hline $\begin{array}{l}\text { Average surplus per } \\
\text { household a }^{\text {a }}\end{array}$ & 10.51 & 10.51 & 18.92 & 25.83 & 42.49 & \\
\hline $\begin{array}{l}\text { Number of } \\
\text { households }\end{array}$ & 823 & 213 & 24 & 131 & 15 & 1206 \\
\hline \multicolumn{7}{|l|}{$\begin{array}{l}\text { Surplus for all } \\
\text { households }\end{array}$} \\
\hline Customer-side $^{\mathrm{a}}$ & - & - & 248.88 & - & 336.15 & 585.03 \\
\hline Supplier-side ${ }^{a}$ & 8649.73 & 2238.63 & 205.20 & 3383.73 & 301.20 & $14,778.49$ \\
\hline Overall surplus a & 8649.73 & 2238.63 & 454.08 & 3383.73 & 637.35 & $15,363.52$ \\
\hline
\end{tabular}

With respect to the survey data, Table 4 gives a descriptive overview of the HEMS acceptance and requirements. Thus, the most important factor for using the HEMS is the sustainability of the solution ( $\mathrm{M}=4.16, \mathrm{SD}=0.65)$. The contribution to environmental protection, the use of renewable energies, and their increase in efficiency are considered rather important. Another determinant motive to use is economic benefit in terms of cost savings $(\mathrm{M}=3.99, \mathrm{SD}=0.74)$. In addition, the possibility to monitor the own energy consumption, information from, and interaction with the HEMS are moderate to rather important criteria $(\mathrm{M}=3.49, \mathrm{SD}=0.71)$. Moderate important motives are additional functions to increase the comfort $(\mathrm{M}=3.04, \mathrm{SD}=0.92)$, like remote control regarding illumination and surveillance. The acceptance for the participatively developed HEMS is slightly positive. The usability is considered comparatively best $(\mathrm{M}=3.61, \mathrm{SD}=0.53)$, while accessibility $(\mathrm{M}=3.25, \mathrm{SD}=0.59)$ and usefulness $(\mathrm{M}=3.12, \mathrm{SD}=0.78)$ are considered rather moderate. The intention to use is also moderate on average, but the measures are slightly wider spread $(\mathrm{M}=3.04, \mathrm{SD}=0.90)$. 
Table 4. HEMS acceptance and requirements descriptive statistics and correlations.

\begin{tabular}{|c|c|c|c|c|c|c|c|c|c|c|c|c|c|c|c|c|}
\hline & & $\mathbf{M}$ & SD & 2 & 3 & 4 & 5 & 6 & 7 & 8 & 9 & 10 & 11 & 12 & 13 & 14 \\
\hline 1 & $\mathrm{COB}$ & 4.46 & 0.42 & 0.25 * & 0.27 * & -0.01 & -0.09 & -0.20 & 0.17 & 0.17 & 0.06 & $0.24^{+}$ & 0.00 & 0.28 * & $0.26^{*}$ & 0.17 \\
\hline 2 & $\mathrm{TST}$ & 3.39 & 0.72 & & $0.41^{* *}$ & $0.18^{+}$ & $-0.35^{* *}$ & $-0.25^{+}$ & 0.33 * & 0.18 & 0.11 & $0.44^{* *}$ & 0.32 * & $0.41^{* *}$ & 0.39 ** & $0.41^{* *}$ \\
\hline 3 & CUR & 3.69 & 0.78 & & & $0.56^{* *}$ & -0.12 & -0.17 & 0.02 & 0.19 & 0.11 & 0.20 & -0.10 & -0.01 & $0.37^{* *}$ & 0.18 \\
\hline 4 & INR & 3.29 & 0.77 & & & & $-0.29^{* *}$ & $0.35^{* *}$ & -0.16 & -0.03 & 0.04 & -0.04 & -0.23 & -0.06 & 0.11 & -0.13 \\
\hline 5 & ANX & 2.12 & 0.66 & & & & & 0.08 & 0.06 & $-0.29 *$ & 0.01 & -0.07 & $0.25^{+}$ & 0.01 & -0.16 & 0.05 \\
\hline 6 & SKE & 2.39 & 0.62 & & & & & & -0.17 & $-0.47^{* *}$ & -0.18 & -0.29 * & -0.13 & -0.16 & $-0.31 *$ & $-0.37^{* *}$ \\
\hline 7 & USF & 3.12 & 0.78 & & & & & & & 0.26 * & 0.28 * & $0.53^{* *}$ & $0.65^{* *}$ & $0.60^{* *}$ & $0.48^{* *}$ & $0.70^{* *}$ \\
\hline 9 & $\mathrm{ACC}$ & 3.25 & 0.59 & & & & & & & & & $0.38^{* *}$ & $0.25^{+}$ & $0.32 *$ & $0.38^{* *}$ & $0.48^{* *}$ \\
\hline 10 & SAV & 3.99 & 0.74 & & & & & & & & & & $0.57^{* *}$ & $0.79^{* *}$ & $0.82^{* *}$ & $0.52 * *$ \\
\hline 11 & CMF & 3.04 & 0.92 & & & & & & & & & & & $0.68^{* *}$ & $0.35^{* *}$ & $0.52 * *$ \\
\hline 12 & $\mathrm{MON}$ & 3.49 & 0.71 & & & & & & & & & & & & $0.62 * *$ & $0.52 * *$ \\
\hline 13 & SUS & 4.16 & 0.65 & & & & & & & & & & & & & $0.49^{* *}$ \\
\hline 14 & ITU & 3.04 & 0.90 & & & & & & & & & & & & & \\
\hline
\end{tabular}

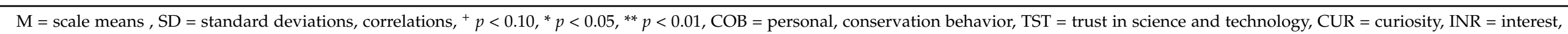

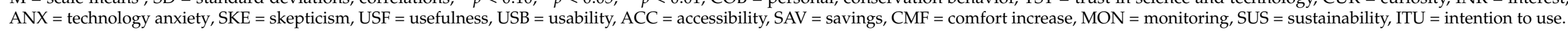




\subsection{Market Potential of the Developed HEMS}

To explore the market potential, a k-means cluster analysis based on the acceptance and requirements dimensions of the developed HEMS is conducted. Thereby, five segments were identified, as depicted in Figure 1.

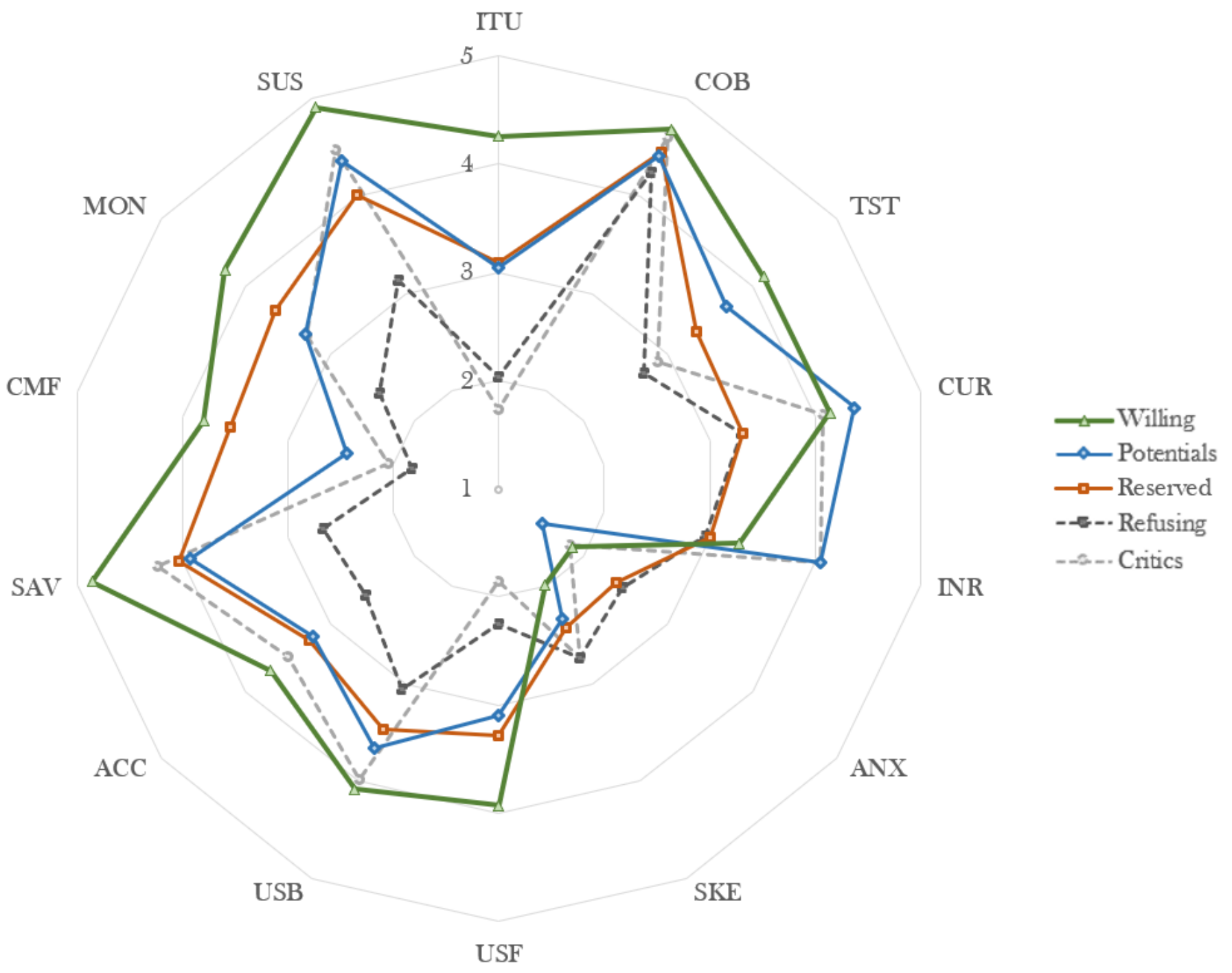

Figure 1. K-means cluster analysis illustrating user segmentation.

Segment "Willing" (17\%): The prototype "Willing" is 44.86 years old (SD = 16.65), and gender is evenly distributed. In this segment, most participants completed vocational school without a school-leaving certificate ( $43 \%)$. They mainly live in single-family houses (57\%). While $47 \%$ live in two-person households, $40 \%$ live together with four or more persons, and none of them live alone. Typical usable floor space of their homes amounts to $158.28 \mathrm{~m}^{2}$ on average $(\mathrm{SD}=78.15)$. For hot water preparation, these users mainly use electric boilers $(47 \%)$, followed by heat pumps $(20 \%)$, and, without exception, all of them $(100 \%)$ own hot water storage. The amount of PV system owners is rather low at only $14 \%$. Participants are most likely to use the HEMS $(\mathrm{M}=4.26, \mathrm{SD}=0.41)$. Their most relevant HEMS requirements are sustainability $(\mathrm{M}=4.91, \mathrm{SD}=0.20)$ and cost savings $(\mathrm{M}=4.86, \mathrm{SD}=0.27)$. They evaluate the HEMS as more useful $(\mathrm{M}=3.93, \mathrm{SD}=0.59)$, more user-friendly $(\mathrm{M}=4.08, \mathrm{SD}=0.51)$, and more accessible $(\mathrm{M}=3.70, \mathrm{SD}=0.51)$ compared to the other segments. While interest in new technologies is only moderately pronounced $(\mathrm{M}=3.28, \mathrm{SD}=0.92)$, there is a rather high level of trust in science and technology in this segment $(\mathrm{M}=4.14, \mathrm{SD}=0.62)$. Furthermore, users in this segment seek possibilities for 
monitoring energy consumption $(\mathrm{M}=4.24, \mathrm{SD}=0.47)$ and for increasing comfort in their home $(\mathrm{M}=3.80, \mathrm{SD}=0.62)$ through the HEMS.

Segment "Potentials" (18\%): Typical "Potentials" are 54.29 years old $(S D=11.15)$ and characterized by a slightly larger number of females (57\%). In this segment, education level is compared to the other segments rather high, $36 \%$ completed a general or vocational school with a school-leaving certificate, and another $36 \%$ completed tertiary education. Half of them (50\%) live in single-family houses, and their typical floor space is $166.26 \mathrm{~m}^{2}$ on average $(\mathrm{SD}=79.34)$. Their hot water preparation happens mostly either with electric boilers $(27 \%)$ or with solar thermal energy $(27 \%)$. Seventy-seven percent use a hot water storage, and one-third (33\%) possess a PV system for energy generation. Persons in this segment are generally open to new technological developments, as curiosity $(\mathrm{M}=4.37$, $\mathrm{SD}=0.47)$ and interest $(\mathrm{M}=4.06, \mathrm{SD}=0.47)$ are comparatively high, and technology anxiety $(\mathrm{M}=\mathrm{M}=1.51, \mathrm{SD}=0.43)$ is rather low. However, the "Potentials" have only limited confidence in the developed HEMS, particularly with regard to usefulness $(\mathrm{M}=3.09, \mathrm{SD}=0.60)$ and usability $(\mathrm{M}=3.66, \mathrm{SD}=0.48)$. Above all, little value is placed on additional functions that are intended to contribute to increased comfort $(\mathrm{M}=2.45, \mathrm{SD}=0.76)$. The intention to use is moderate $(\mathrm{M}=3.04, \mathrm{SD}=0.68)$.

Segment "Reserved" (39\%): The prototype "Reserved" is more likely to be characterized by female users $(67 \%)$ aged 47.94 , on average $(\mathrm{SD}=13.58)$, who tend to have completed an apprenticeship (53\%). Persons in this segment are more likely to live in larger single-family houses $(78 \%)$, as the typical floor space of their homes amounts $158.55 \mathrm{~m}^{2}(\mathrm{SD}=88.81)$. They prepare hot water mostly with wood or pellet stoves $(27 \%)$, and $89 \%$ possess hot water storage. However, only $6 \%$ of this segment uses a PV system for energy generation. "Reserved" users have comparatively high requirements towards the HEMS solution, as the requirements of comfort increase $(\mathrm{M}=3.55, \mathrm{SD}=0.44)$ and monitoring $(\mathrm{M}=3.65, \mathrm{SD}=0.38)$ are more important for users of this segment compared to other users. Their attitudes are more defensive in terms of curiosity $(M=3.31, S D=0.69)$, interest $(M=3.00, S D=0.52)$, and trust in new technologies $(\mathrm{M}=3,34, \mathrm{SD}=0.43)$. This results in a positive evaluation but only a moderately pronounced actual intention of use the HEMS solution $(\mathrm{M}=3.09$, $\mathrm{SD}=0.54)$. With $39 \%$ share, it is the largest target group.

Segment "Refusing" (17\%): The "Refusing" user is typically male (67\%), with an average age of 55.43 (SD = 13.30), who tend to have completed an apprenticeship (69\%). Persons in this segment live either in single-family houses $(53 \%)$ or apartments $(47 \%)$ with floor spaces of $134.87 \mathrm{~m}^{2}$ on average (SD = 56.75). Residents in this segment mostly use either electric boilers or solar thermal energy for hot water preparation, and $73 \%$ have hot water storage. Twenty percent of them own a PV system. The intention to use the HEMS solution is rather low $(\mathrm{M}=2.03, \mathrm{SD}=0.36)$.

Segment "Critics" (9\%): The prototype "Critics" is comparatively young, at 38.81 years of age on average $(\mathrm{SD}=14.01)$. There is a slight preponderance of male users within this group (57\%). They either have completed an apprenticeship (57\%) or a tertiary education $(43 \%)$ and live predominantly in apartments (43\%) or single-family houses (43\%). Persons in this segment tend to use either electric boilers (29\%) or heat pumps (29\%) to prepare hot water, and most possess hot water storage (86\%). Compared to the others, in this segment, the share of PV system is the highest at $43 \%$. The intention to use is rather low in this segment $(\mathrm{M}=1.73, \mathrm{SD}=0.65)$.

The detailed segment profiles are summarized in Table 5. 
Table 5. Profiling the user segments and dominating demographic characteristics.

\begin{tabular}{|c|c|c|c|c|c|}
\hline & $\begin{array}{c}\text { Willing } \\
(\mathbf{1 7 . 2 0} \%)\end{array}$ & $\begin{array}{c}\text { Potentials } \\
(\mathbf{1 8 . 2 8 \%})\end{array}$ & $\begin{array}{c}\text { Reserved } \\
(38.72 \%)\end{array}$ & $\begin{array}{l}\text { Refusing } \\
(17.20 \%)\end{array}$ & $\begin{array}{l}\text { Critics } \\
(8.60 \%)\end{array}$ \\
\hline \multicolumn{6}{|l|}{ Gender } \\
\hline Female $^{a}$ & 53.33 & 57.14 & 65.63 & 33.33 & 42.86 \\
\hline Male $^{\mathrm{a}}$ & 46.76 & 42.86 & 34.38 & 66.67 & 57.14 \\
\hline Age (years) ${ }^{b}$ & $44.86(16.65)$ & $54.29(11.15)$ & $47.94(13.58)$ & $55.43(13.30)$ & $38.81(14.01)$ \\
\hline \multicolumn{6}{|l|}{ Education } \\
\hline Apprenticeship ${ }^{a}$ & 21.43 & 7.14 & 53.13 & 68.75 & 57.14 \\
\hline Intermediate vocational school ${ }^{a}$ & 42.86 & 21.43 & 18.75 & 6.25 & - \\
\hline School-leaving certificate ${ }^{\mathrm{a}}$ & 21.43 & 35.71 & 12.50 & 12.50 & - \\
\hline University degree $^{\mathrm{a}}$ & 14.29 & 35.71 & 15.63 & 12.50 & 42.86 \\
\hline \multicolumn{6}{|l|}{ Housing } \\
\hline Flat $^{\mathrm{a}}$ & 28.57 & 28.57 & 15.63 & 46.67 & 42.86 \\
\hline Single-family house ${ }^{a}$ & 57.14 & 50.00 & 78.13 & 53.33 & 42.86 \\
\hline Two-family house or larger ${ }^{a}$ & 14.29 & 21.43 & 6.25 & - & 14.29 \\
\hline \multicolumn{6}{|l|}{ Household size } \\
\hline 1 person $^{\mathrm{a}}$ & - & 13.33 & 16.13 & 6.25 & - \\
\hline 2 persons ${ }^{a}$ & 46.67 & 40.00 & 35.48 & 43.75 & 66.67 \\
\hline 3 persons $^{\text {a }}$ & 13.33 & 20.00 & 19.35 & 12.50 & 16.67 \\
\hline 4 or more persons ${ }^{a}$ & 40.00 & 26.67 & 29.03 & 37.50 & 16.67 \\
\hline \multicolumn{6}{|l|}{ Hot water preparation } \\
\hline Electric boiler ${ }^{a}$ & 46.67 & 26.67 & 12.12 & 26.67 & 28.57 \\
\hline Heat pump ${ }^{a}$ & 20.00 & 13.33 & 18.18 & - & 28.57 \\
\hline $\mathrm{Oil}^{\mathrm{a}}$ & 13.33 & 6.67 & 15.15 & 20.00 & 14.29 \\
\hline Wood or pellet stove ${ }^{a}$ & 6.67 & 6.67 & 27.27 & 6.67 & 14.29 \\
\hline Solar thermal energy ${ }^{a}$ & 6.67 & 26.67 & 12.12 & 26.67 & 14.29 \\
\hline Other $^{\mathrm{a}}$ & 6.67 & 20.00 & 15.15 & 20.00 & - \\
\hline \multicolumn{6}{|l|}{ Hot water storage } \\
\hline yes $^{\text {a }} \quad$ o & 100.00 & 76.92 & 89.66 & 73.33 & 85.71 \\
\hline no $^{a}$ & - & 10.34 & 26.67 & 23.08 & 14.29 \\
\hline \multicolumn{6}{|l|}{$P V$} \\
\hline yes $^{a}$ & 14.29 & 33.33 & 6.25 & 20.00 & 42.86 \\
\hline no ${ }^{a}$ & 85.71 & 66.67 & 93.75 & 80.00 & 57.14 \\
\hline \multicolumn{6}{|c|}{ Acceptance scales ( 1 = strongly disagree, $5=$ strongly agree) } \\
\hline Intention to use $\mathrm{c}^{\mathrm{c}}$ & $4.26(0.41)$ & $3.04(0.68)$ & $3.09(0.54)$ & $2.03(0.36)$ & $1.73(0.65)$ \\
\hline Personal conservation behavior ${ }^{\mathrm{c}}$ & $4.68(0.36)$ & $4.41(0.51)$ & $4.46(0.33)$ & $4.25(0.45)$ & $4.60(0.46)$ \\
\hline Trust in science and technology ${ }^{c}$ & $4.14(0.62)$ & $3.70(0.67)$ & $3.34(0.43)$ & $2.71(0.45)$ & $2.88(0.89)$ \\
\hline Curiosity ${ }^{\mathrm{c}}$ & $4.14(0.52)$ & $4.37(0.47)$ & $3.31(0.69)$ & $3.30(0.81)$ & $4.07(0.61)$ \\
\hline Interest ${ }^{c}$ & $3.28(0.92)$ & $4.06(0.47)$ & $3.00(0.52)$ & $2.96(0.68)$ & $4.06(0.74)$ \\
\hline Technology anxiety ${ }^{c}$ & $1.87(0.55)$ & $1.51(0.43)$ & $2.39(0.57)$ & $2.46(0.56)$ & $1.84(0.92)$ \\
\hline Skepticism ${ }^{c}$ & $1.98(0.79)$ & $2.34(0.44)$ & $2.42(0.63)$ & $2.73(0.36)$ & $2.73(0.51)$ \\
\hline Usefulness ${ }^{c}$ & $3.93(0.59)$ & $3.09(0.60)$ & $3.28(0.54)$ & $2.26(0.23)$ & $1.86(0.27)$ \\
\hline Usability $^{\mathrm{c}}$ & $4.08(0.51)$ & $3.66(0.48)$ & $3.47(0.41)$ & $3.06(0.38)$ & $3.99(0.42)$ \\
\hline Accessibility ${ }^{c}$ & $3.70(0.51)$ & $3.20(0.51)$ & $3.25(0.54)$ & $2.58(0.43)$ & $3.49(0.62)$ \\
\hline \multicolumn{6}{|c|}{ Requirements scales ( $1=$ not important at all, $5=$ very important) } \\
\hline Savings ${ }^{c}$ & $4.86(0.27)$ & $3.93(0.67)$ & $4.03(0.34)$ & $2.67(0.40)$ & $4.24(0.57)$ \\
\hline Comfort increase ${ }^{\mathrm{c}}$ & $3.80(0.62)$ & $2.45(0.76)$ & $3.55(0.44)$ & $1.82(0.61)$ & $2.05(0.36)$ \\
\hline Monitoring ${ }^{c}$ & $4.24(0.47)$ & $3.29(0.67)$ & $3.65(0.38)$ & $2.41(0.27)$ & $3.28(0.89)$ \\
\hline Sustainability ${ }^{c}$ & $4.91(0.20)$ & $4.36(0.50)$ & $4.02(0.45)$ & $3.14(0.35)$ & $4.47(0.50)$ \\
\hline
\end{tabular}




\subsection{Estimation of the Socially-Accepted Potential}

In this section, the socially-accepted potential is estimated. Figure 2 represents the economical surplus per household, which is used to estimate the socially-accepted potential in the sample area.

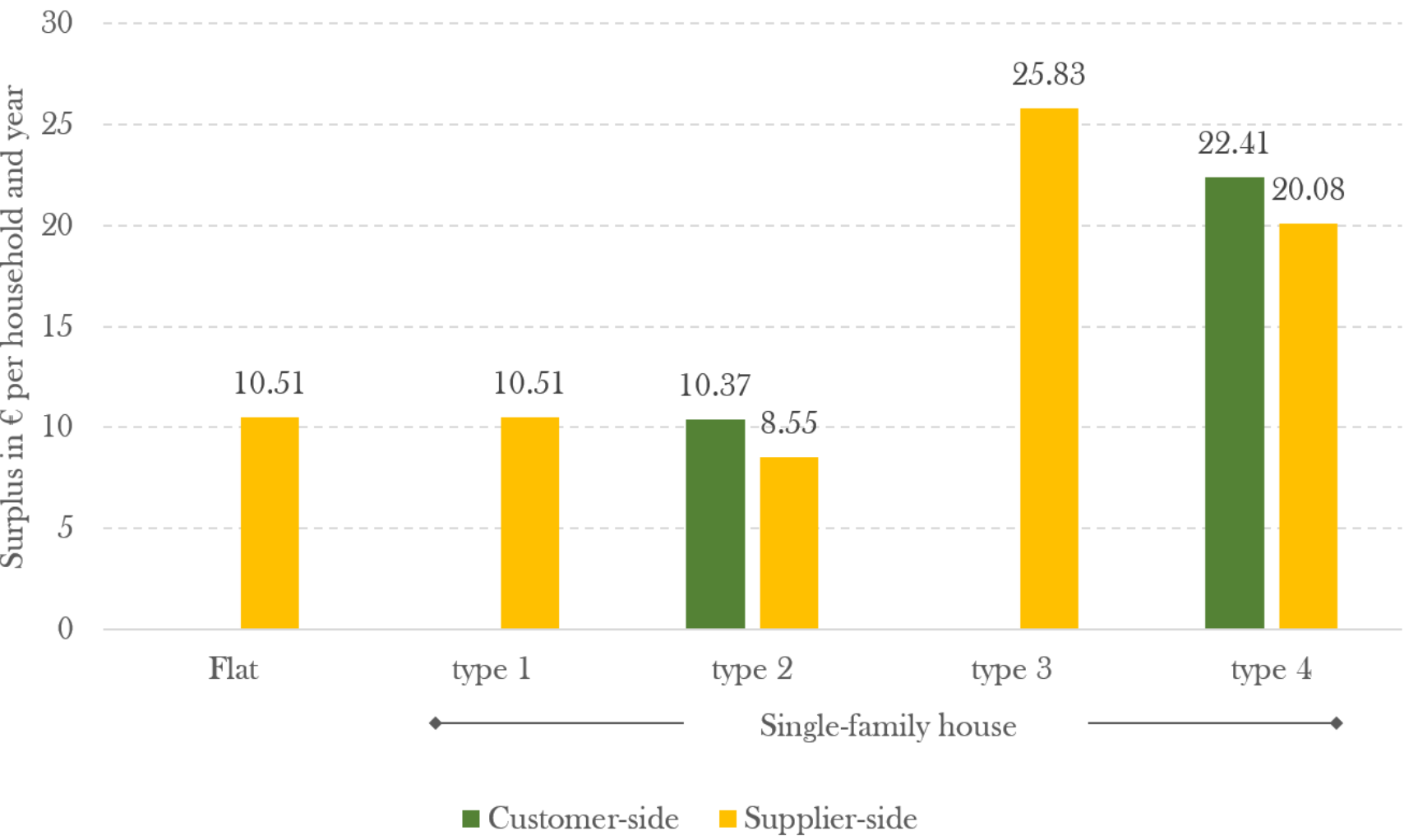

Figure 2. Surplus per household and year.

Assuming that the target group for the developed HEMS solution consists of the Segment "Willing" (17\%) and the segment "Potentials" $(18 \%)$, in total, $35 \%$ of the described techno-economic optimization potential for households can be seen as socially-accepted techno-economic potential. This yields the numbers in Table 6 including the shiftable power load. Households with social acceptance and a PV system achieve a total surplus of $195.01 € / a$ on the customer-side.

Table 6. Socially-accepted techno-economic potential of households.

\begin{tabular}{|c|c|c|c|c|c|c|}
\hline \multirow{2}{*}{ Household Type } & \multirow{2}{*}{ Flat } & \multicolumn{4}{|c|}{ Single-Family House } & \multirow{2}{*}{ Tota } \\
\hline & & Type 1 & Type 2 & Type 3 & Type 4 & \\
\hline Number of households & 823 & 213 & 24 & 131 & 15 & 1206 \\
\hline Number of households with social acceptance & 288 & 75 & 8 & 46 & 5 & 422 \\
\hline \multicolumn{7}{|l|}{$\begin{array}{l}\text { Surplus for all households with social } \\
\text { acceptance }\end{array}$} \\
\hline Customer-side $^{\mathrm{a}}$ & - & - & 82.96 & - & 112.05 & 195.01 \\
\hline Supplier-side ${ }^{\mathrm{a}}$ & 3026.88 & 788.25 & 68.40 & 1188.18 & 100.40 & 5172.11 \\
\hline Overall surplus a & 3026.88 & 788.25 & 151.36 & 1188.18 & 212.45 & 5367.12 \\
\hline \multicolumn{7}{|l|}{ Shiftable load } \\
\hline Per household ${ }^{b}$ & 4.5 & 4.5 & 4.5 & 2.3 & 2.3 & \\
\hline Per household type ${ }^{b}$ & 1296.0 & 337.5 & 36.0 & 105.8 & 11.5 & 1786.80 \\
\hline
\end{tabular}




\section{Discussion}

It is essential for the operation of the electricity system to ensure a steady balance between production and consumption. In addition, distribution grids, which were originally designed for the distribution of energy coming from large central power plants to the consumers, are faced with the task of being able to accommodate decentralized feed-in. In order to master both challenges in the energy system of the future with a high proportion of fluctuating wind and PV energy, the use of customer-side flexibility can help. In order to be able to make use of this flexibility, on the one hand, appropriate business models based on the technical solutions are necessary; on the other hand, the question of user acceptance arises. Both aspects have been discussed and quantified in this paper.

The survey participants are generally rather to very environmentally conscious, but they are only moderately interested in technological developments. However, curiosity and openness towards new technologies are present on several occasions. They are generally quite open to the developed HEMS solution, although acceptance is moderate, in general. The most important motives of the users are sustainability and the potential monetary benefits of the HEMS. Moderate to rather important factors for the use of the HEMS solution are possibilities to monitor one's own energy consumption and to increase the comfort of the home through additional functions.

A market segmentation indicates $17 \%$ of the end users that show a high acceptance and intention to use the developed HEMS. This target group, the "Willing", could be reached by highlighting the monetary advantages of the HEMS solution and the ongoing savings potential. Since this user group puts just as much emphasis on sustainability, both monetary and idealistic motives are addressed, which are often seen as rather contrary. The "Willing" show also the highest trust in science and technology among all segments. In addition, they perceive the HEMS' usefulness as highest among all participants and are the least skeptical. Furthermore, they also find great value in using HEMSs, with all requirements factors being the highest among all segments (savings, comfort increase, monitoring, and sustainability).

Additionally, the target group "Potentials", which has a share of $18 \%$, must be considered. Although they are generally very interested in technology and energy solutions, their perceived usefulness of the HEMS is rather moderate. As their main motive to use the HEMS is sustainability, this target group should be informed properly about the possibilities that HEMSs give them to save energy. The feedback function of HEMSs, which gives advice to users in order to change energy consumption behavior in a sustainable way, should be emphasized in communication campaigns aimed at them. Due to the fact that one third of this segment generates energy through PV systems, the automatic scheduling of home energy consumption adjusted to weather forecasts can be a convincing argument for homeowners, as this function balances energy generation and consumption in a sustainable manner.

Another target group to consider are the "Reserved". Although they show only a moderate intention to use HEMSs, they form the largest segment with $39 \%$. Compared to the other groups, their technology anxiety is slightly more noticeable, which could be the reason of their weak intention. However, same as among the "Willing" and the "Potentials", their highest motivation factors are monetary savings and sustainability. To address this target group, more effort must be made than with standard marketing campaigns. It is recommended to conduct a dialogue with the "Reserved" to gain more insight into the reservation factors that influence them. Due to participatory procedures, e.g., when it comes to the development of HEMSs, this target group could be introduced to the advantages and usefulness of HEMSs, which eventually decreases their skepticism towards this technology.

Regarding the remaining two segments ("Refusing" and "Critics"), it is likely more difficult to motivate them to use HEMSs. First of all, possible additional functionalities of HEMSs have to be investigated in order to provide additional benefits which could convince these groups. In addition, careful market research needs to be conducted to find out why skepticism is rather high in these three segments, in order to find counter arguments for 
them. Furthermore, it has to be pointed out to these segments that the HEMS solutions are actually affordable, since the perceived accessibility was rather low in these groups. However, whether the effort to convince these two segments is profitable has to be considered.

Cost savings and sustainability are the most important drivers for all target groups to use HEMSs. In general, these benefits need to be communicated precisely in marketing campaigns. In the case study at hand, the developed HEMS solution yields the considerably larger monetary surplus on the supplier-side, which results particularly from its system support optimization focus. Hence, the results of the social and techno-economical analyses are slightly contradictory. Whilst, on the supplier-side, the largest monetary surplus by the HEMS is generated from single-family houses with installed heat pumps, on the customerside, only the integration of the HEMS in combination with a PV system is linked with a monetary surplus. However, a shiftable load of nearly 1.8 MW is still notable and can make a significant contribution to grid stability for local energy networks.

\section{Conclusions}

From the authors' point of view, the following conclusions can be drawn: (i) The monetary benefit of load shifting and the associated exploitation of low electricity prices for the supplier or of own generation (if available) for the end user is manageable, and the current electricity market design rewards systemically useful load behavior for households only to a very limited extent. New market opportunities (e.g., energy communities) could improve this situation. (ii) Persons in the "Willing" segment should not only be addressed as consumers but also as influencers with the goal to make other people in their environment aware of the usefulness and the value of HEMSs in a broader context. In order to encourage them to communicate the advantages of HEMSs, offering monetary benefits in return could be an appropriate instrument. (iii) The developed HEMS is in general accepted in 35\% of the user segments, namely the "Willing" and the "Potentials". However, there is still room for improvement, e.g., considering the "Reserved" segment. Appropriate market models, educational measures, and different communication strategies for each segment could help here to unleash further socially-accepted potential for an increased use of flexibility.

Even with the limited potential of socially-accepted techno-economic potential in households, the shiftable load of nearly 1.8 MW supports an efficient and reliable system operation and, thus, a sustainable energy supply using renewable energies.

Author Contributions: Conceptualization, C.P.; methodology, C.P. and M.P.; validation, C.P., M.P., and L.G.; software, C.P. and M.P.; formal analysis, C.P. and M.P.; investigation, C.P. and M.P.; resources, C.M., I.V.T., and T.P.K.; data curation, C.P. and M.P.; writing-original draft preparation, C.P., M.P., C.M., I.V.T., and T.P.K.; writing—review and editing, M.P. and L.G.; visualization, C.P. and M.P.; supervision, L.G.; project administration, M.P.; funding acquisition, M.P. All authors have read and agreed to the published version of the manuscript.

Funding: This research was funded by the Austrian Climate and Energy Fund grant number 846142.

Acknowledgments: The authors thank Marion Rabelhofer and Alexandra Baldwin, who provided important preliminary work and feedback during the development of this article.

Conflicts of Interest: The authors declare no conflict of interest.

\section{Abbreviations}

The following abbreviations are used in this manuscript:

ACC accessibility

ANX technology anxiety

$\mathrm{CMF}$ comfort increase

$\mathrm{COB}$ personal conservation behavior

CUR curiosity 


$\begin{array}{ll}\text { EAI } & \text { Environmental Attitudes Inventory } \\ \text { HEMS } & \text { home energy management system } \\ \text { INR } & \text { interest } \\ \text { ITU } & \text { intention to use } \\ \text { M } & \text { mean } \\ \text { MON } & \text { monitoring } \\ \text { PV } & \text { photovoltaic } \\ \text { SAV } & \text { savings } \\ \text { SD } & \text { standard deviation } \\ \text { SKE } & \text { skepticism } \\ \text { SUS } & \text { sustainability } \\ \text { TAM } & \text { Technology Usage Inventory } \\ \text { TST } & \text { trust in science and technology } \\ \text { USB } & \text { usability } \\ \text { USF } & \text { usefulness }\end{array}$

\section{References}

1. Hsieh, E.; Anderson, R. Grid flexibility: The quiet revolution. Electr. J. 2017, 30, 1-8. [CrossRef]

2. Andrey, C.; Attard, P.; Bardet, R.; Fournié, L.; Khallouf, P. Mainstreaming RES Flexibility Portfolios; Technical Report; European Commission: Brussels, Belgium, 2017.

3. Hall, M.; Geissler, A. Load control by demand side management to support grid stability in building clusters. Energies 2020, 13, 5112. [CrossRef]

4. Finck, C.; Li, R.; Kramer, R.; Zeiler, W. Quantifying demand flexibility of power-to-heat and thermal energy storage in the control of building heating systems. Appl. Energy 2018, 209, 409-425. [CrossRef]

5. Straub, A.; Volmer, E. User's perspective on home energy management systems. Environments 2018, 5, 126. [CrossRef]

6. Washizu, A.; Nakano, S.; Ishii, H.; Hayashi, Y. Willingness to pay for home energy management systems: A survey in New York and Tokyo. Sustainability 2019, 11, 4790. [CrossRef]

7. Anvari-Moghaddam, A.; Monsef, H.; Rahimi-Kian, A. Optimal smart home energy management considering energy saving and a comfortable lifestyle. IEEE Trans. Smart Grid 2015, 6, 324-332. [CrossRef]

8. Jiang, J.C.; Kantarci, B.; Oktug, S.; Soyata, T. Federated Learning in Smart City Sensing. Sensors 2020, 20, 6230. [CrossRef] [PubMed]

9. Ellabban, O.; Abu-Rub, H. Smart grid customers' acceptance and engagement: An overview. Renew. Sustain. Energy Rev. 2016, 65, 1285-1298. [CrossRef]

10. Buchanan, K.; Banks, N.; Preston, I.; Russo, R. The British public's perception of the UK smart metering initiative: Threats and opportunities. Energy Policy 2016, 91, 87-97. [CrossRef]

11. Fredericks, D.; Fan, Z.; Woolley, S.; De Quincey, E.; Streeton, M. A decade on, how has the visibility of energy changed? Energy feedback perceptions from UK focus groups. Energies 2020, 13, 2566. [CrossRef]

12. Park, E.S.; Hwang, B.Y.; Ko, K.; Kim, D. Consumer acceptance analysis of the home energy management system. Sustainability 2017, 9, 2351. [CrossRef]

13. Al-Ali, A.R.; Zualkernan, I.A.; Rashid, M.; Gupta, R.; Alikarar, M. A smart home energy management system using IoT and big data analytics approach. IEEE Trans. Consum. Electron. 2017, 63, 426-434. [CrossRef]

14. Elkazaz, M.; Sumner, M.; Pholboon, S.; Davies, R.; Thomas, D. Performance assessment of an energy management system for a home microgrid with PV generation. Energies 2020, 13, 3436. [CrossRef]

15. Betancourt, R.O.J.; López, J.M.G.; Espejo, E.B.; Sánchez, A.C.; Laureano, E.V.; Pérez, S.S.; Aguilar, L.C. Iot-based electricity bill for domestic applications. Sensors 2020, 20, 6178. [CrossRef]

16. Park, H. Human comfort-based-home energy management for demand response participation. Energies 2020, 13, 2463. [CrossRef]

17. Yoo, Y.; Jung, S.; Kang, S.; Song, S.; Lee, J.; Han, C.; Jang, G. Dispatchable Substation for Operation and Control of Renewable Energy Resources. Appl. Sci. 2020, 10, 7938. [CrossRef]

18. Widén, J. Improved photovoltaic self-consumption with appliance scheduling in 200 single-family buildings. Appl. Energy 2014, 126, 199-212. [CrossRef]

19. Radl, J.; Fleischhacker, A.; Revheim, F.H.; Lettner, G.; Auer, H. Comparison of profitability of PV electricity sharing in renewable energy communities in selected European countries. Energies 2020, 13, 5007. [CrossRef]

20. Shah, A.S.; Nasir, H.; Fayaz, M.; Lajis, A.; Shah, A. A review on energy consumption optimization techniques in IoT based smart building environments. Information 2019, 10, 108. [CrossRef]

21. Shareef, H.; Ahmed, M.S.; Mohamed, A.; Al Hassan, E. Review on Home Energy Management System Considering Demand Responses, Smart Technologies, and Intelligent Controllers. IEEE Access 2018, 6, 24498-24509. [CrossRef]

22. Ayala-Gilardón, A.; Mora-López, L.; Sidrach-De-Cardona, M. Analysis of a photovoltaic self-consumption facility with different net metering schemes. Int. J. Smart Grid Clean Energy 2017, 6, 47-53. [CrossRef]

23. Han, J.; Choi, C.S.; Park, W.K.; Lee, I.; Kim, S.H. Smart home energy management system including renewable energy based on ZigBee and PLC. IEEE Trans. Consum. Electron. 2014, 60, 198-202. [CrossRef] 
24. Herrmann, M.R.; Brumby, D.P.; Oreszczyn, T.; Gilbert, X.M. Does data visualization affect users' understanding of electricity consumption? Build. Res. Inf. 2018, 46, 238-250. [CrossRef]

25. Machorro-Cano, I.; Alor-Hernández, G.; Paredes-Valverde, M.A.; Rodríguez-Mazahua, L.; Sánchez-Cervantes, J.L.; OlmedoAguirre, J.O. HEMS-IoT: A big data and machine learning-based smart home system for energy saving. Energies 2020, $13,1097$. [CrossRef]

26. Carli, R.; Dotoli, M.; Jantzen, J.; Kristensen, M.; Ben Othman, S. Energy scheduling of a smart microgrid with shared photovoltaic panels and storage: The case of the Ballen marina in Samsø. Energy 2020, 198, 117188. [CrossRef]

27. Kim, M.; Parkt, S.; Choi, J.K.; Lee, J. Energy independence of energy trading system in microgrid. In Proceedings of the 2017 IEEE Innovative Smart Grid Technologies-Asia, ISGT-Asia 2017, Auckland, New Zealand, 4-7 December 2017; pp. 1-4. [CrossRef]

28. Hosseini, S.M.; Carli, R.; Dotoli, M. Robust Optimal Energy Management of a Residential Microgrid Under Uncertainties on Demand and Renewable Power Generation. IEEE Transact. Automat. Sci. Eng. 2020, 1-20. [CrossRef]

29. Ford, R.; Pritoni, M.; Sanguinetti, A.; Karlin, B. Categories and functionality of smart home technology for energy management. Build. Environ. 2017, 123, 543-554. [CrossRef]

30. Ruano, A.; Hernandez, A.; Ureña, J.; Ruano, M.; Garcia, J. NILM techniques for intelligent home energy management and ambient assisted living: A review. Energies 2019, 12, 2203. [CrossRef]

31. Samuel, O.; Javaid, S.; Javaid, N.; Ahmed, S.H.; Afzal, M.K.; Ishmanov, F. An efficient power scheduling in smart homes using jaya based optimization with time-of-use and critical peak pricing schemes. Energies 2018, 11, 3155. [CrossRef]

32. Oikonomou, V.; Becchis, F.; Steg, L.; Russolillo, D. Energy saving and energy efficiency concepts for policy making. Energy Policy 2009, 37, 4787-4796. [CrossRef]

33. Poortinga, W.; Steg, L.; Vlek, C.; Wiersma, G. Household preferences for energy-saving measures: A conjoint analysis. J. Econ. Psychol. 2003, 24, 49-64. [CrossRef]

34. Trotta, G. Factors affecting energy-saving behaviours and energy efficiency investments in British households. Energy Policy 2018, 114, 529-539. [CrossRef]

35. Baedeker, C.; Piwowar, J.; Themann, P.; Grinewitschus, V.; Krisemendt, B.; Lepper, K.; Zimmer, C.; von Geibler, J. Interactive design to encourage energy efficiency in offices: Developing and testing a user-centered building management system based on a living lab approach. Sustainability 2020, 12, 6956. [CrossRef]

36. Rabelhofer, M.; Pfeiffer, C.; Stöller, J. On the challenges of empowering citizens in technological innovation matters. In Proceedings of the 13th Conference on Sustainable Development of Energy, Water and Environment Systems, Palermo, Italy, 30 September4 October 2018; pp. 1-10.

37. Mancini, F.; Basso, G.L.; De Santoli, L. Energy use in residential buildings: Characterisation for identifying flexible loads by means of a questionnaire survey. Energies 2019, 12, 2055. [CrossRef]

38. Fambri, G.; Badami, M.; Tsagkrasoulis, D.; Katsiki, V.; Giannakis, G.; Papanikolaou, A. Demand flexibility enabled by virtual energy storage to improve renewable energy penetration. Energies 2020, 13, 5128. [CrossRef]

39. Stinner, S.; Huchtemann, K.; Müller, D. Quantifying the operational flexibility of building energy systems with thermal energy storages. Appl. Energy 2016, 181, 140-154. [CrossRef]

40. Nuytten, T.; Claessens, B.; Paredis, K.; Van Bael, J.; Six, D. Flexibility of a combined heat and power system with thermal energy storage for district heating. Appl. Energy 2013, 104, 583-591. [CrossRef]

41. Lee, E.; Baek, K.; Kim, J. Evaluation of Demand Response Potential Flexibility in the Industry Based on a Data-Driven Approach. Energies 2020, 13, 6355. [CrossRef]

42. D’hulst, R.; Labeeuw, W.; Beusen, B.; Claessens, S.; Deconinck, G.; Vanthournout, K. Demand response flexibility and flexibility potential of residential smart appliances: Experiences from large pilot test in Belgium. Appl. Energy 2015, 155, 79-90. [CrossRef]

43. Cao, Z.; O'rourke, F.; Lyons, W.; Han, X. Home energy management system incorporating heat pump using real measured data. Sensors 2019, 19, 2937. [CrossRef]

44. Puchegger, M. Demonstration of a Smart Connection of Urban Electricity, Natural Gas E District Heating Networks to Functional Electricity Storage Facilities; Publishable Final Report of the Project "Hybrid Grids Demo"; Austrian Climate and Energy Fund: Vienna, Austria, 2019.

45. Osier, G.; Museux, J.-M.; Seoane, P.; Verma, V. Cross-Sectional and Longitudinal Weighting for the EU-SILC Rotational Design. Available online: https://www.iser.essex.ac.uk/files/survey/ulsc/methodological-research/mols-2006/scientific-socialprogramme/papers/Osier.pdf (accessed on 2 September 2020).

46. Statistics Austria. Register-Based Labour Market Statistics 2018-Households and Families. 2018. Available online: https://www. statistik.at/web_en/statistics /PeopleSociety/population/population_censuses_register_based_census_register_based_labour_ market_statistics/index.html (accessed on 13 November 2020).

47. Milfont, T.L.; Duckitt, J. The environmental attitudes inventory: A valid and reliable measure to assess the structure of environmental attitudes. J. Environ. Psychol. 2010, 30, 80-94. [CrossRef]

48. Kothgassner, O.D.; Felnhofer, A.; Hauk, N.; Kastenhofer, E.; Gomm, J.; Kryspin-Exner, I. TUI. Technology Usage Inventory; Technical Report; ICARUS Research Team: Vienna, Austria, 2012.

49. Davis, F.D.; Bagozzi, R.P.; Warshaw, P.R. User Acceptance of Computer Technology: A Comparison of Two Theoretical Models. Manag. Sci. 1989, 35, 982-1003. [CrossRef] 
50. Pfeiffer, C.; Rabelhofer, M. Participation in Energy Transition-Challenges within the Scope of Smart Grids. In Proceedings of the 3rd South East European Conference on Sustainable Development of Energy, Water and Environment Systems, Novi Sad, Serbia, 30 June-3 July 2018; pp. 1-9.

51. Puchegger, M. Joint utilization of demand side flexibility of heating devices and heating grids with benefits for energy suppliers and customers by. In Proceedings of the 15th IAEE European Conference 2017, Vienna, Austria, 3-6 September 2017.

52. Statistics Austria. Energy Consumption of Households 2017/2018. Available online: https://www.statistik.at/web_en/statistics/ EnergyEnvironmentInnovationMobility / energy_environment/energy/energy_consumption_of_households/index.html (accessed on 11 June 2019).

53. Statistics Austria. Stock of Buildings and Dwellings. 2017. Available online: http://www.statistik.at/web_en/statistics/ PeopleSociety/housing/stock_of_buildings_and_dwellings/index.html (accessed on 13 November 2020).

54. Biermayr, P.; Dißauer, C.; Eberl, M.; Enigl, M.; Leonhartsberger, K.; Maringer, F.; Moidl, S.; Schmidl, C.; Strasser, C.; Weiss, W.; et al. Innovative Energietechnologien in Österreich-Marktentwicklung 2016; Technical Report; Federal Ministry Republic of Austria for Transport, Innovation and Technology: Vienna, Austria, 2017. 